\title{
TRABALHO DOCENTE E ATENDIMENTO EDUCACIONAL ESPECIALIZADO: UMA ANÁLISE DA PRODUÇÃO ACADÊMICA NO PORTAL DE TESES E DISSERTAÇÕES DA CAPES - 2013 A 2016
}

\author{
Osni Oliveira Noberto da Silva (UNEB)* \\ Theresinha Guimarães Miranda (UFBA)** \\ Miguel Angel Garcia Bordas (UFBA)***
}

\begin{abstract}
RESUMO
O objetivo deste artigo é conhecer, através de uma revisão sistemática, as pesquisas relacionadas com trabalho docente e Atendimento Educacional Especializado, entre os anos de 2013 e 2016. Observou um aumento no número de pesquisas que relacionam esses 2 elementos. Entretanto, houve um predomínio dos estudos nas regiões Sul e Sudeste em detrimento das outras regiões do País. Foi possível perceber que os estudos encontrados sobre trabalho docente e AEE tiveram como foco os seguintes elementos: políticas públicas, prática pedagógica, formação de professores, tecnologias assistivas, discurso dos professores, identidade docente, bem-estar docente, avaliação e produção do conhecimento. Entre os instrumentos metodológicos encontrados, ainda que variando em nomenclatura e abordagem, percebeu-se prioritariamente o uso da entrevista, presente em 30 estudos, seguido da análise documental em 13, da observação em 15, da análise documental em 13, do grupo focal em 9, do diário de campo e da dinâmica conversacional em 1 cada.
\end{abstract}

Palavras-chave: Trabalho docente. Atendimento educacional especializado. Revisão.

\begin{abstract}
TEACHING WORK AND SPECIALIZED EDUCATIONAL ATTENDANCE: AN ANALYSIS OF THE ACADEMIC PRODUCTION IN THE PORTAL OF THESES AND DISSERTATIONS OF CAPES - 2013 TO 2016

The objective of this article is to know, through a systematic review, the research related to teaching work and Specialized Educational Attendance, between the years
\end{abstract}

\footnotetext{
* Mestre e Doutorando em Educação pela Universidade Federal da Bahia (UFBA). Professor do Departamento de Ciências Humanas da Universidade do Estado da Bahia (UNEB-Campus IV). Líder do Grupo de Estudos, Pesquisa e Extensão em Educação Especial e Educação Física Adaptada (GEPEFA/UNEB). Integrante do Grupo de Estudos sobre Educação Inclusiva e Necessidades Educacionais Especiais (GEINE/UFBA).E-mail: osni_edfisica@yahoo.com.br

** Pós-doutora pela Umea University, Suécia. Doutora em Educação pēla Universidade de São Paulo (USP). Professora do Programa de Pós-graduação em Educação da Universidade Federal da Bahia (UFBA). Integrante do Grupo de Estudos sobre Educação Inclusiva e Necessidades Educacionais Especiais (GEINE/UFBA). E-mail: tmiranda@ufba.br

*** Pós-doutor pela Universitat Autònoma de Barcelona. Doutor em Filosofia pela Universidad Complutense de Madrid. Professor do Programa de Pós-graduação em Educação da Universidade Federal da Bahia (UFBA). Integrante do Grupo de Estudos sobre Educação Inclusiva e Necessidades Educacionais Especiais (GEINE/UFBA). E-mail: magbordas@gmail.com
} 
of 2013 to 2016. It observed an increase in the number of researches that relate these two elements. However, there was a predominance of studies in the south and southeast regions to the detriment of other regions of the country. It was possible to notice that the studies found on Teaching Work and ESA focused on the following elements: Public Policies, Pedagogical Practice, Teacher Training, Assistive Technologies, Teachers' Discourse, Teaching Identity, Teaching Well-Being, Evaluation, and Knowledge Production. Among the methodological instruments found, although varying in nomenclature and approach, the use of the interview, present in 30 studies, followed by the documentary analysis in 13 , the observation in 15 , the documentary analysis in 13, the focus group in 9, the field diary and the conversational dynamics in 1 each. Keywords: Teaching work. Specialized educational assistance. Review.

\section{RESUMEN}

\section{TRABAJO DOCENTE Y ATENDIMIENTO EDUCACIONAL ESPECIALIZADO: UN ANÁLISIS DE LA PRODUCCIÓN ACADÉMICA EN EL PORTAL DE TESES Y DISERTACIONES DE LA CAPES - 2013 A 2016}

El objetivo de este artículo es conocer, a través de una revisión sistemática, las investigaciones relacionadas con trabajo docente y Atención Educativa Especializada, entre los años de 2013 a 2016. Observó un aumento en el número de investigaciones que relacionan esos 2 elementos. Sin embargo, hubo un predominio de los estudios en la región sur y sudeste en detrimento de las otras regiones del país. Se puede observar que los estudios encontrados sobre Trabajo docente y AEE tuvieron como foco los siguientes elementos: Políticas Públicas, Práctica pedagógica, Formación de profesores, Tecnologías Asistivas, Discurso de los profesores, Identidad docente, Bienestar docente, Evaluación, y Producción del conocimiento. Entre los instrumentos metodológicos encontrados, aunque variando en nomenclatura y enfoque, se percibió prioritariamente el uso de la entrevista, presente en 30 estudios, seguido del análisis documental en 13, la observación en 15, el análisis documental en 13, el grupo focal en 9, el diario de campo y la dinámica conversacional en 1 cada uno.

Palabras clave: Trabajo docente. Asistencia educativa especializada. Revisión.

\section{Introdução}

Entre o final do século XX e início do XXI, a Educação Especial tem recebido uma importante atenção, tanto da mídia quanto de autoridades políticas e educadores, muito por conta dos avanços nas discussões acerca das políticas públicas e, consequentemente, a implantação de serviços educacionais específicos, sendo o mais importante o Atendimento Educacional Especializado (AEE), que é disponibilizado aos alunos com deficiência (BERNARDES; CORDEIRO, 2016).

Por ser um serviço relativamente novo, que ainda necessita de constante aperfeiçoamento, que demanda uma série de intervenções específicas por conta da necessidade de cada um dos estudantes da Educação Especial, muitas ações e compreensões acerca da implantação, reconhecimento, possibilidades do AEE ainda carecem de estudos mais aprofundados. O próprio docente é levado a um processo de ressignificação e reconhecimento do seu trabalho. Isto porque, além de ser necessário proporcionar as condições materiais para a concretização do AEE nas escolas, é imprescindível também que existam condições favoráveis para a execução do trabalho docente a fim de propiciar a acessibilidade aos conhecimentos para os alunos, independente das suas limitações (BERNARDES; CORDEIRO, 2016). 
Assim, o objetivo deste artigo é levantar, através de uma revisão sistemática, a produção acadêmica, em nível de mestrado e doutorado, relacionada com trabalho docente e Atendimento Educacional Especializado nos últimos anos. A importância desse movimento de conhecer o que já foi produzido reside no fato de perceber para onde as pesquisas estão se direcionando, ou seja, quais os objetivos dos estudos, qual a metodologia utilizada, quais as conclusões e, por fim, explicitar a lacuna que estes estudos deixaram, para que outras pesquisas venham ajudar a preencher.

\section{Metodologia}

Foi feito um estudo, do tipo revisão sistemática, durante o período de 20 de fevereiro a 4 de março de 2017, sobre a produção acadêmica brasileira no Portal de Dissertações e Teses da Capes, dentro do recorte temporal de pesquisas defendidas entre 2013 e 2016. Foram utilizados os descritores "Trabalho docente" e "Atendimento Educacional Especializado", os dois grupos de palavras juntos em uma busca chamada de booleana .

$\mathrm{Na}$ busca inicial o banco de dados apresentou 3703 registros nas mais diversas áreas e que fugiam muito do tema ao qual se buscava. Ao refinar os resultados apenas para a área de Educação, os registros diminuíram para 774. Com a leitura dos títulos dos trabalhos foram eliminados 722, restando 52 . Em seguida foi feita a leitura dos resumos, gerando a eliminação de mais 11 estudos, chegando ao valor final de 41 pesquisas que se aproximam da temática inicialmente pesquisada.

Dessas 41 pesquisas, 36 são dissertações de Mestrado e 5 são teses de Doutorado. Sobre o local onde esses estudos foram desenvolvidos, temos a região Sul com 17 pesquisas ( 8 em Santa Catarina, 6 no Rio Grande do Sul e 3 no Paraná), seguida pelo Sudeste com 11 (5 no Espirito Santo, 2 em São Paulo, 3 em Minas Gerais e 1 no Rio de Janeiro), Centro-Oeste com 7 (Distrito Federal com 4, Goiás com 2 e Mato Grosso do Sul com 1), Nordeste com 4 (Pernambuco, Paraíba, Piauí e Bahia com 1 cada) e Norte com 2 (Pará e Rondônia).

Essas pesquisas têm como elemento central o Trabalho docente e o Atendimento Educacional Especializado e se subdividem em diferentes focos.

\section{Análise e discussão das pesquisas sobre trabalho docente e AEE}

Sobre o foco em Políticas Públicas temos 12 estudos (ALVES, 2015; BARRETTA, 2013; BUIATTI, 2013; FELLINI, 2013; FETTBACK, 2013; LUNA, 2015; NASCIMENTO, 2013; REVELANTE, 2013; ROCHA, 2014; TIBOLA, 2014; VAZ, 2013; VIEGAS, 2005).

$\mathrm{Na}$ dissertação de Barretta (2013) o objetivo geral foi entender como são implementadas as propostas de políticas públicas de educação especial dentro do paradigma da inclusão em escolas públicas do município de Frederico Westphalen-RS. A metodologia constou de dados coletados nas entrevistas com um representante da gestão da Secretaria Municipal de Educação da cidade e os gestores e professores de uma escola Municipal e outra Estadual. Os resultados encontrados indicam que, nas duas escolas estudadas, a implementação e efetivação de políticas públicas de educação especial na perspectiva inclusiva ocorre de forma lenta, mas ainda assim com avanços positivos e significativos.

Em contraste temos a pesquisa de Buiatti (2013) que analisou documentos legais, principalmente, $o$ Decreto $n^{\circ} 7.611$, que dispõe sobre o AEE, sobre as políticas públicas da educação inclusiva e da educação especial. Além disso, foram realizadas entrevistas com as profissionais de AEE e professores do ensino regular de uma escola estadual e de uma escola municipal da cidade de Uberlândia-MG. Na análise documental, percebeu-se que a legislação estabelece como dever do Estado o sistema de ensino inclusivo, sem discriminação, pautado na igualdade de oportunidade e dando destaque às funções dos profissionais do AEE e à garantia de formação continuada dos professores. Com a pesquisa de campo pode ser constatado que é total a consideração de que o AEE contribui para o aprendizado dos estudantes. Entretanto, as participantes enfatizaram alguns problemas e limitações no trabalho do AEE, tais como a dificuldade de interlocução entre a sala comum e o ensino no $\mathrm{AEE}$, a falta de materiais, o espaço físico inadequado, a ausência de formação continuada para os professores e dificuldades referentes à elaboração de intervenções e à avaliação dos estudantes. Os 
resultados sugerem que os documentos se mostram diferentes da realidade analisada. A autora sugere que os gestores das escolas revejam suas concepções e reorganizem as estruturas educacionais a fim de efetivar a escolarização de todos.

Seguindo a mesma linha, a dissertação de Fellini (2013) visou apresentar os encaminhamentos que têm subsidiado a implantação do Atendimento Educacional Especializado como modalidade de Educação Especial no contexto da Educação Básica na região Nordeste do Brasil. Os instrumentos de coleta de dados constaram de um questionário aplicado a professores de três escolas municipais, localizadas em três estados da região Nordeste do Brasil, que estavam matriculados no Curso de Pós-Graduação em Atendimento Educacional Especializado da Universidade Estadual de Maringá, na modalidade a distância, além de fotografias e entrevistas com os docentes das salas de recursos multifuncionais dessas escolas. A análise dos dados demonstrou diferenças significativas entre os documentos e os dados da pesquisa de campo. As escolas não dispõem de acessibilidade nem de profissionais habilitados. Assim, o estudo conclui que a educação inclusiva não está sendo realmente implementada nessas escolas, o que para a autora é entendido como uma "in(ex)clusão consciente e legalmente aplicada" (FELLINI, 2013, p. 8).

A pesquisa de Fettback (2013) teve como objetivo analisar a aplicabilidade das diretrizes que aparecem nos documentos que norteiam a Política Nacional de Educação Especial na Perspectiva da Educação Inclusiva, com o intuito de compreender o relacionamento entre família, escola e AEE. Participaram da pesquisa representantes de 15 famílias (uma tia, um irmão, um pai e doze mães), 3 professoras de AEE, 46 professores do ensino regular, 5 auxiliares de educadores monitores e 15 estudantes, num total de 84 sujeitos. O local da pesquisa foi a cidade de Joinville-SC. Como instrumentos para a coleta dos dados foram utilizados: diário de campo, caderno de notas, questionário, roteiro de questões para a entrevista e ficha de observação. Os resultados do estudo indicaram que pais e professores desconhecem o serviço de AEE e houve divergências no que diz respeito às opiniões sobre a parceria entre eles.
Já na dissertação de Nascimento (2013) os resultados foram mais positivos. $\mathrm{O}$ objetivo do estudo foi problematizar as políticas de Educação Especial e as práticas pedagógicas do município de Nova Venécia-ES. A metodologia utilizada foi a pesquisa-ação e os instrumentos de coleta de dados foram: grupo focal, observação participante e entrevistas semiestruturadas. Os resultados do estudo indicam que a política municipal se encontra em processo de materialização e muitas alternativas, tendo em vista processos mais inclusivos, vêm sendo experimentadas. Segundo a autora, existe um forte investimento municipal em formações continuadas e arranjos organizativos facilitadores da oferta do AEE no espaço das salas de recursos multifuncionais. Essas condições se configuram como movimentos promissores.

Seguindo por outro caminho, a dissertação de Revelante (2013) teve por objetivo analisar como as políticas públicas inclusivas têm efeitos na produção e governamento de professores do AEE. Neste estudo o autor optou pelas noções de governamentalidade e governamento desenvolvidas por Michel Foucault. A metodologia foi a análise de documentos, principalmente a Política Nacional de Educação Especial na Perspectivada Educação Inclusiva, de 2008, o Parecer CNE/CEB $n^{\circ} 13 / 2009$, a Resolução $n^{\circ} 04 / 2009$ e o Decreto $n^{\circ}$ $7.611 / 2011$. O estudo conclui trazendo à reflexão a formação docente como uma medida biopolítica que se apodera do AEE como tecnologia de governamento. Por isso a autora expõe a necessidade de formar os professores que deverão ser "capazes de atender toda e qualquer demanda de alunos, isto é, a formação docente para o AEE é um dispositivo de governamentalidade neoliberal que estabelece novas táticas de governo, governo dos outros e o autogoverno" (RELEVANTE, 2013, p. 91).

Vaz (2013), em sua dissertação de mestrado, objetivou compreender a concepção de professor de Educação Especial (EE) contida nos documentos oficiais que expressam essa política. Com o Decreto $\mathrm{n}^{\circ} 6.571$ essa modalidade de ensino foi direcionada para o Atendimento Educacional Especializado (AEE) nas salas de recursos multifuncionais. A metodologia utilizada foi a análise dos documentos oficiais, as produções acadêmicas e os dados do Censo Escolar de 2012. As conclusões do estudo 
foram de que a Política Educacional em vigência apresenta uma ênfase no professor do AEE e uma diminuição da importância do professor de EE nas escolas regulares, o que, para o autor, produz um novo consenso no campo da educação.

A dissertação de Rocha (2014) teve como objetivo analisar o processo de interpretação e tradução da política de Educação Especial na perspectiva da Educação Inclusiva pelos professores de Salas de Recursos Multifuncionais (SRM) da Rede Municipal de Ensino de Florianopolis-SC. O instrumento de coleta de dados foi um grupo focal com 26 professores. Os resultados demonstraram, no que diz respeito à formação dos professores para atuar na SRM, que os docentes avaliaram que a política trouxe algumas dificuldades ao criar um professor especializado generalista, com competência para atuar com todas as deficiências e em diferentes níveis de ensino. Em contrapartida, as diretrizes aumentaram a finalidade do atendimento, mas reforçaram a individualização do ensino. Quanto à organização do AEE, foi notado que o atendimento de que a rede dispõe está de acordo com as orientações dos documentos. Contudo, existe uma relação de conflito com a sala regular e falta uma ligação entre o ensino oferecido nas classes comuns e nas SRM.

Tibola (2014) buscou caracterizar as políticas públicas e sua contextualização com a política educacional inclusiva, assim como identificar sua presença em documentos importantes, em nível nacional e internacional. O universo de pesquisa foram as escolas públicas do município de Vicente Dutra-RS e os sujeitos, seus gestores. Foi utilizada a pesquisa bibliográfica, de tipo documental, a observação sistemática das instituições e o questionário estruturado. Segundo os resultados, no que diz respeito ao $\mathrm{AEE}$, os gestores sentem falta de base e apoio técnico e de formação adequada, dificuldades acerca da maneira de avaliar e, principalmente, a ausência de projetos bem definidos, tanto do poder público estadual como municipal.

A tese de Viegas (2005) teve como objetivo entender o processo de reconfiguração das proposições que vinculam a educação especial e a educação regular dos alunos com deficiência, considerando os contextos, os espaços decisórios de uma rede de ensino do município de Cachoeirinha-RS. Foi utilizada a análise documental e a entrevista semiestruturada. $\mathrm{O}$ estudo concluiu que o reordenamento da educação especial nessa rede municipal de ensino foi feito com base na obrigatoriedade da dupla matrícula como argumento legal que deu o impulso necessário para tornar obrigatória a escolarização dos alunos com deficiência nas escolas regulares e nas classes comuns, mudar o perfil do alunado da educação especial, elaborar a proposta pedagógica do Centro e dar importância à participação da comunidade e da família, além da seriedade dada à formação docente.

Alves (2015), em sua dissertação, descreveu e analisou a proposta de trabalho do Atendimento Educacional Especializado (AEE) para os alunos público-alvo da Educação Especial, matriculados nas escolas municipais de Ensino Fundamental do $1^{\circ}$ ao $5^{\circ}$ ano da cidade de Uberlândia-MG, entre o período de 2005 e 2014. Na metodologia foi utilizada a análise documental da legislação que regula a Educação Especial no Brasil e no município de Uberlândia, a entrevista semiestruturada com duas coordenadoras responsáveis pela Educação Especial no município e o questionário para os professores do AEE e para os professores da classe comum. Os resultados demonstraram que as escolas têm-se articulado para: a oferta do AEE, a ênfase na importância da relação entre professores do AEE e da classe comum e a formação continuada focada no entendimento do trabalho com a diferença humana que vá além da participação de alunos com deficiência na escola.

Entretanto, resultado oposto dos últimos trabalhos apresentados pode ser observado na tese de Luna (2015), que objetivou avaliar o processo de implementação da política pública das SRM do município de Jequié-BA. Na metodologia foram utilizadas: análise documental, entrevista semiestruturada, discussão de grupo focal e observação direta. Os sujeitos da pesquisa foram a coordenadora de educação especial do município e as professoras da SRM. Os resultados expuseram que, mesmo que o trabalho tenha surtido efeito e ajudado a superar algumas mazelas, existem muitas dificuldades no funcionamento e organização das SRM, tais como: falta de uma formação mais qualificada, muitos afazeres dos docentes e sua consequente sobrecarga de trabalho, falta de cooperação dos 
docentes das classes comuns, falta de material, a falta de integração de uma equipe multidisciplinar, dentre outros fatores.

Essas pesquisas apresentaram resultados conflitantes entre si, demonstrando que em diferentes locais de pesquisa as políticas públicas alternavam entre aplicações lentas, mas com resultados significativos, e exemplos de fracassos que exigem mudanças profundas em sua estruturação.

Sobre a Prática pedagógica do professor de AEE, foram encontrados 10 estudos (ALBUQUERQUE, 2014; BERNARDES, 2014; COSTA, 2015; COTONHOTO, 2014; LYRA, 2013; PALMA, 2016; PORTO, 2014; SILVA, S., 2015; SOUZA, 2013; ZUQUI, 2013).

A dissertação de Lyra (2013) teve por objetivo analisar, através de um estudo de caso, como tem sido realizado o atendimento de alunos com altas habilidades/superdotação nas escolas estaduais da Região Metropolitana de Londrina, no Paraná. O estudo de caso teve como foco o Núcleo de Atividades de Altas Habilidades/Superdotação (NAAH/S) do Paraná, que conta com 10 participantes que trabalham nesse núcleo. Utilizando como instrumento de coleta de dados a entrevista com um roteiro semiestruturado e análise por meio da técnica de análise de conteúdo, foi possível observar que existe pouco referencial teórico específico sobre $\mathrm{o}$ atendimento dos NAAH/S, falta de manutenção dos equipamentos do núcleo e a necessidade de aquisição de novos computadores, impressoras, mobiliários, materiais de trabalho, recursos financeiros e profissionais. Além disso, observou-se a necessidade de maior investimento na qualificação dos professores do ensino regular no sentido de uma formação mais adequada para a identificação do aluno e seu encaminhamento ao atendimento. Entretanto, foi possível verificar aspectos positivos do trabalho desenvolvido no NAAH/S, tais como o envolvimento dos profissionais, as práticas aplicadas e as parcerias estabelecidas.

A dissertação de Souza (2013) tem como objetivo investigar e analisar a funcionalidade das salas de recursos multifuncionais (SRM) no processo de inclusão, assim como as influências delas para o desenvolvimento educacional dos alunos com déficit cognitivo. Foram utilizadas observações em duas salas de aula comuns e na SRM em uma escola estadual da cidade de Uberlândia-MG, além de entrevistas com as professoras destas salas. A análise dos dados do estudo constatou, segundo o autor, que os alunos, tanto em uma turma que tem professores que se preocupam com a inclusão, quanto outros que não se preocupam, estão aprendendo o conteúdo. Foram percebidos também diversos entraves para atender às normas do Ministério da Educação no que diz respeito à organização do trabalho pedagógico das SRM e aos requisitos de formação do professor especializado para atuar nestas salas. Assim, os resultados permitem questionar se as salas de recursos, da maneira que hoje funcionam, colaboram para o processo de inclusão de alunos com déficit cognitivo nas salas de aula comuns e no desenvolvimento de suas potencialidades educacionais.

O estudo de Zuqui (2013) buscou esclarecer a dinâmica da escolarização de alunos público-alvo da educação especial com foco no AEE e a relação entre a sala de aula comum e as SRM das escolas da rede municipal da cidade de São Mateus-ES. Os instrumentos metodológicos de coleta de dados foram o grupo focal, a observação e as entrevistas semiestruturadas. Nos resultados destaca-se a busca, no âmbito da rede municipal, de uma educação na perspectiva da Educação Inclusiva. Foi observado que existe uma relação entre as atividades planejadas e desenvolvidas no AEE e o currículo da classe comum e a colaboração entre as professoras especialistas e os professores da sala de aula comum. Outros pontos também aparecem nos resultados, como a dificuldade de acesso ao transporte público pelos alunos, necessidade de uma maior discussão do papel e da função do professor do atendimento educacional especializado e os limites e potencialidades que as SRM oferecem como serviço de apoio.

Albuquerque (2014), em sua tese de doutorado, analisou a prática pedagógica inclusiva realizada no interior da rede municipal de ensino de Jaboatão dos Guararapes, em Pernambuco. Foi realizado um estudo de caso envolvendo 39 participantes. A investigação desenvolveu-se em quatro fases, tendo sido utilizados os seguintes instrumentos: análise documental, observação, entrevista semiestruturada e entrevista associativa. A técnica de análise de conteúdo foi utilizada na análise dos dados coletados. 
De acordo com os resultados obtidos na pesquisa, a autora afirma que, na escola estudada, a prática pedagógica inclusiva não atinge seus objetivos de forma satisfatória, pois na prática prevalecem experiências perpetuadas no modelo tradicional, na perspectiva médica e terapêutica da deficiência. Além disso, mesmo com as políticas públicas educacionais estabelecendo diretrizes especificas para o processo de escolarização do aluno com deficiência, existe incoerência entre o discurso da inclusão e a prática, visto que as práticas desenvolvidas no AEE são burocratizadas, solitárias, improvisadas e amenizadoras de conflitos.

A dissertação de Bernardes (2014) teve como objetivo conhecer o trabalho docente do AEE na rede municipal de ensino de Joinville-SC através das vozes das próprias professoras. A metodologia utilizada foi um questionário com perguntas abertas e fechadas realizado com 34 professoras e a entrevista semiestruturada com uma das supervisoras do Núcleo de Educação Especial. Os resultados evidenciaram que o trabalho do AEE ocorre de forma isolada, que não existe um padrão de procedimentos para o direcionamento dos estudantes para o AEE e que os indicativos de aprendizagem dos estudantes na sala de aula comum são maiores do que os do trabalho do AEE.

Situações adversas também foram encontradas na tese de Cotonhoto (2014), que teve como objetivo compreender a proposta e a prática curricular do AEE enquanto auxílio na educação da criança pequena com deficiência e Transtornos Globais do Desenvolvimento (TGD). O local da pesquisa foi o Centro Municipal de Educação Infantil (CMEI), situado em Vitória-ES. Os sujeitos participantes foram crianças de 3 a 7 anos matriculadas no CMEI, sendo 6 crianças surdas, 7 crianças com manifestações de TGD e 1 criança com Síndrome de Down, além de 2 professores de educação especial, 1 professora bilíngue, 1 instrutor surdo, professores regentes do turno da manhã CMEI e 2 pedagogos. A metodologia foi o uso da pesquisa-ação colaborativa com a utilização de observação e entrevistas. Os resultados destacam a falta de formação dos professores e o desconhecimento deles acerca da proposta curricular da educação infantil. Além disso, foi possível perceber, segundo a autora, práticas pedagógicas descontextualizadas e fragmentadas desenvolvidas na SRM, que dificultavam o trabalho da classe comum.

A dissertação de Porto (2014) teve como objetivo caracterizar o AEE ofertado em SRM nas escolas regulares da rede estadual de ensino de uma cidade do norte do Paraná. O estudo foi realizado em oito escolas. Para coleta dos dados foram utilizados o questionário fechado e a entrevista semiestruturada. Os participantes foram as 9 professoras que atuam nessas SRM. O estudo concluiu que o AEE ofertado em SRM é relevante para o processo de inclusão escolar dos alunos, ainda que algumas dificuldades tenham aparecido acerca da sua organização e funcionamento, tais como o espaço físico inadequado, a formação sem um planejamento aparente dos professores, o público-alvo que se constitui majoritariamente de alunos sem deficiência e a falta de importância dada ao trabalho colaborativo entre professor especialista e professor da classe comum. Ainda que não tenha sido o objetivo do estudo, os resultados encontrados atingem diretamente as condições de trabalho dos professores.

A pesquisa de Costa (2015) analisou a implantação das SRM no município do Rio de Janeiro entre os anos de 2013 e 2014. O instrumento usado na coleta de dados foi a análise documental de grupos focais promovidos pelo Observatório da Educação Especial do Rio de Janeiro (OEERJ), além da entrevista semiestruturada de duas professoras das SRM. Os resultados da pesquisa demonstraram o impacto que uma política pública pode gerar nas práticas de inclusão em educação. A análise das falas das professoras demonstrou que parece existir o interesse na inclusão dos alunos do AEE, por parte das professoras de Educação Especial. A autora, na análise de dados, afirmou que existem divergências entre os profissionais que se declaram receptivos aos valores de inclusão e outros, um grupo menor, que visivelmente não demonstraram tal interesse.

Dados semelhantes sobre a relação entre os professores de AEE e os das turmas regulares foram encontrados na dissertação de Silvana Silva (2015), que teve por objetivo geral identificar e descrever a estrutura de atendimento e o trabalho pedagógico desenvolvido em SRM implantadas em 2 escolas da cidade de Araraquara-SP. Foram utilizados como instrumentos de coleta de dados a observação estruturada não participante e o questionário misto com 
questões abertas e fechadas. Os sujeitos do estudo foram as professoras especialistas em Educação Especial. Os resultados da pesquisa indicaram que a cidade estudada tem uma equipe de professores especialistas com formação adequada, que estão em constante aperfeiçoamento e com larga experiência em Educação Especial. As salas de recursos multifuncionais são bem equipadas e atendem, em sua maioria, a alunos com déficit cognitivo. Entretanto, a relação de colaboração entre as professoras especialistas e os professores das classes regulares parece ser insuficiente.

Palma (2016), em sua dissertação, teve como objetivo analisar o Atendimento Educacional Especializado que é desenvolvido em escolas do campo, através de um Estudo de Caso tendo como universo 3 escolas do campo localizadas em um município do interior de São Paulo; os participantes sujeitos foram 31 professores de ensino regular, 17 responsáveis pelos alunos atendidos pelo serviço de AEE e a própria pesquisadora. Como instrumentos de coleta dos dados foram utilizados questionários, observação, registro fotográfico e análise dos documentos escolares. $\mathrm{O}$ estudo apresentou como principais resultados: apenas uma escola possui espaço apropriado para o funcionamento da Sala de Recursos Multifuncional; o número de professores de Educação Especial que atende à demanda é insuficiente; os alunos participam do AEE no mesmo turno da escola regular por conta das dificuldades do transporte; os familiares acabam não reconhecendo a dificuldade dos filhos com deficiência.

Nesses estudos podemos perceber que a prática pedagógica do trabalho do professor no AEE também sofre, em sua maioria, dificuldades. A falta de estrutura, a pouca colaboração com os professores da sala comum e a falta de formação específica são os principais entraves descobertos nos trabalhos.

Nas pesquisas que relacionam trabalho docentes e AEE, foram encontrados 6 estudos com foco nas Tecnologias assistivas (CALDAS, 2015; CÂNDIDO, 2015; FONSECA, 2015; REIS, 2014; SALOMÃO, 2013; SILVA, C., 2014).

Na dissertação de Salomão (2013) o objetivo foi investigar como o AEE e o uso do computador como recurso pedagógico podem potencializar a ação do professor no atendimento ofertado ao aluno com NEE na sala de recursos de uma escola pública localizada na zona central de Brasília. A metodologia utilizada foi a pesquisa-ação, os sujeitos participantes foram uma professora de AEE, uma professora de classe regular e um aluno com deficiência intelectual atendido pelas duas profissionais. Como instrumentos de coleta foram usados a observação participante, a entrevista semiestruturada e a dinâmica conversacional. Os resultados da pesquisa evidenciaram a importância da utilização do computador como recurso pedagógico no favorecimento do processo de aprendizagem do aluno e alertaram para a necessidade de investir na formação do professor para atuar com essa tecnologia.

A dissertação de Reis (2014) teve como objetivo entender como a Tecnologia Assistiva (TA) tem sido utilizada pelas professoras de AEE, contribuindo na escolarização dos alunos da Educação Especial nas salas de recursos multifuncionais no Sudeste goiano. Os dados foram coletados a partir de entrevista coletiva, envolvendo 13 professoras de AEE, da rede estadual de ensino de Catalão-GO e cidades jurisdicionadas à Subsecretaria Regional de Educação de Catalão. Os resultados da pesquisa direcionam para a necessidade de formação docente voltada ao uso da TA, pois essa ausência na formação dificulta o domínio dos docentes sobre os recursos tecnológicos, e para a ausência de espaços físicos satisfatórios para o AEE.

Na dissertação de Cleudia Silva (2014), o autor procurou descobrir de que forma é utilizada a Tecnologia Assistiva nas salas de AEE. Os sujeitos participantes foram 3 professoras da rede municipal de Teresina-PI. Os instrumentos utilizados na pesquisa foram a entrevista semiestruturada e a observação não participante. Os principais resultados encontrados indicam que as docentes utilizam mais a Tecnologia Assistiva considerada de baixa complexidade e baixo custo, tendo destacado como empecilhos para o desenvolvimento dessa atividade a falta de um trabalho interligado dentro da escola, a sobrecarga de trabalho no AEE e a ausência do acompanhamento familiar.

Caldas (2015), em sua tese de doutorado, analisou como a TA computacional é utilizada no AEE e como é feita a formação docente para trabalhar com esses recursos. Foram utilizados como instrumentos de coleta de dados os grupos focais da pesquisa inaugural do Observatório Nacional de Educação 
Especial do Estado de São Paulo (ONEESP), o questionário online e a entrevista semiestruturada. Foram 89 professores participantes na pesquisa do ONEESP, 30 professores na pesquisa-formação do ONEESP e 2 professores para aplicação da entrevista semiestruturada. Os resultados apontaram que uma pequena parte do conjunto de professores que atuam nas SRM obteve formação para o uso das tecnologias computacionais em sua prática pedagógica, o que acabou por deixar a maioria insegura em relação ao uso dessa ferramenta.

Na dissertação de Cândido (2015) o objetivo foi analisar o uso do software GRID2, ferramenta de Comunicação Aumentativa Alternativa (CAA) oferecida pela Secretaria de Estado de Educação do Distrito Federal (SEDF) para algumas escolas públicas e observar a importância desta tecnologia na inclusão escolar de um estudante com Necessidades Educacionais Específicas (NEE). A metodologia empregada foi a pesquisa-ação. O local do estudo foi uma SRM de uma escola de Ensino Fundamental da cidade de Ceilândia-DF e os sujeitos foram uma professora do AEE, uma professora de classe regular, o estudante que é aluno das duas docentes e a mãe deste aluno. Os resultados do estudo apontaram para a urgência em se investir na formação docente para o uso de Tecnologias Assistivas, em especial do software GRID 2, e indicou a necessidade de formação docente nas salas comuns para utilização de Sistemas de Comunicação Alternativa em sua prática pedagógica.

Fonseca (2015), em sua dissertação, analisou o AEE e o uso das tecnologias nas SRM no ensino médio do Distrito Federal (DF). Como estratégias de pesquisa foram utilizadas a análise documental, o questionário, a entrevista semiestruturada e o grupo de discussão. Os sujeitos da pesquisa foram os professores e estudantes da SRM. Os resultados indicaram alguns problemas: alegação dos professores de que os materiais pedagógicos das SRM são muito infantis para alunos do ensino médio, que as orientações da Secretaria de Educação do Distrito Federal entram em conflito com as normas do MEC e que o AEE parece servir apenas como reforço escolar dos conteúdos da sala de aula regular.

Os estudos sobre tecnologias assistivas demonstram que essa é uma área de grande crescimento e pode colaborar enormemente no trabalho do pro- fessor de AEE e no desenvolvimento educacional dos alunos, bastando para isso uma formação que garanta o aprendizado e o domínio das tecnologias.

Sobre o foco em formação de professores foram encontrados 5 estudos (ALMEIDA, 2014; ALVES, 2013; BATISTA, 2013; RIBEIRO, 2015; SILVA, M., 2014).

$\mathrm{Na}$ dissertação de Alves (2013) o objetivo foi analisar a formação continuada de professores que trabalham nas SRM e as implicações nas suas práticas pedagógicas no contexto de 3 escolas estaduais referências em educação inclusiva na cidade de Belém-PA. Os sujeitos do estudo foram 10 professores de Salas de Recursos Multifuncionais. As técnicas de coleta de dados foram o grupo focal com os professores e a entrevista com dois coordenadores representantes da Coordenadoria de Educação Especial. Os resultados encontrados indicaram que ainda existem, dentre os sujeitos pesquisados, professores apenas com nível médio, ainda que a legislação determine que o professor tenha formação em nível superior. Assim, a autora explica que mesmo que o Estado desenvolva a formação continuada dos docentes, ainda não têm sido suficiente para atender as demandas.

Uma situação um pouco mais favorável apareceu na pesquisa de Batista (2013), que analisou a formação e o trabalho do professor no AEE desenvolvido na Sala de Recursos Multifuncionais (SRM) da cidade de Porto Velho-RO. Como metodologia foram realizadas 36 entrevistas, além de observações e análise documental. Os resultados demonstram que mesmo que os professores tenham obtido títulos de especializações em Educação Especial, ainda apresentam dificuldades do ponto de vista da formação. Segundo a autora, isso ocorre porque um profissional dificilmente consegue dominar o trabalho pedagógico para todos os tipos de deficiência e/ou necessidades educacionais especiais.

A dissertação de Almeida (2014) teve por objetivo conhecer a formação dos professores que atuam nas Salas de Recursos Multifuncionais de escolas públicas estaduais no município de Campos Belos-GO, principalmente no que diz respeito ao uso das Tecnologias da Informação e Comunicação como apoio ao processo de ensino-aprendizagem. Os instrumentos de coleta de dados foram a análise 
documental, a observação simples e a entrevista semiestruturada. Os resultados do estudo direcionam para a urgência de uma reestruturação da formação docente, principalmente no que diz respeito ao uso da Tecnologia Assistiva.

O estudo de Marcia Silva (2014) teve como objetivo investigar os processos formativos dos professores de Goiás no período de 1999 a 2012. Como estratégia metodológica foi utilizada uma ficha de identificação para descrever o perfil das professoras, uma entrevista com questões disparadoras e foi analisada a legislação de Goiás e dados sobre os cursos de formação promovidos. Os dados levantados apontaram que ainda que o estado de Goiás exija formação em nível superior para atuar nas Salas de Recursos Multifuncionais, isso não é seguido à risca no caso de atuação com o AEE. Em relação aos cursos de formação ofertados pelo estado, pôde-se apreender que a formação inicial foi considerada deficitária e insuficiente e a política de formação a distância, implementada pelo governo federal não tem garantido o acesso dos professores às instituições públicas de ensino superior.

Ribeiro (2015), em sua dissertação, teve como objetivo geral verificar a capacidade dos cursos de formação do AEE em formar professores autônomos e conscientizados para a prática inclusiva. O recurso metodológico utilizado para coleta dos dados foi a entrevista semiestruturada, aplicada a 4 professores que atuam no AEE na rede pública de um município próximo à cidade de Campina Grande-PB. Os resultados do estudo apontaram que alguns cursos de formação continuada em AEE não têm um direcionamento voltado à formação de um professor conscientizado e autônomo para uma prática inclusiva.

Os estudos apresentados, que tratam do Trabalho docente e AEE sob a ótica da formação, em geral demonstraram diversas dificuldades, desde a falta de cursos de formação continuada até dificuldades na concepção e execução de tais cursos. Ainda que se tratem de lócus diferentes entre eles, todos apontam para a urgente necessidade de se pensar em uma formação qualificada para o Atendimento Educacional Especializado.

Sobre a ótica dos discursos dos professores temos 3 estudos (FUCK, 2014; RABOCK, 2016; SILVA, M., 2015).
O estudo de Fuck (2014) teve como objetivo investigar o funcionamento do AEE nas Salas de Recursos Multifuncionais, tendo como base a concepção dos professores da sala de aula comum. A metodologia constou de um questionário aplicado a 144 professores do $1^{\circ}$ ao $5^{\circ}$ ano da rede municipal de Joinville-SC que possuíam estudantes atendidos nas salas de recursos e uma entrevista semiestruturada com uma das supervisoras da Educação Especial da Secretaria de Educação do Município. Os resultados apontaram que $92 \%$ dos docentes entendiam o AEE como potencializador de aprendizagem e desenvolvimento. Entretanto, notou-se falta de interação com a sala comum.

A dissertação de Mara Silva (2015) teve como objetivo compreender o papel do AEE no processo de escolarização de alunos com deficiência nas escolas regulares, na perspectiva dos professores deste atendimento. Foram pesquisadas 31 professoras de AEE das escolas estaduais do Município de Chapecó-SC por meio de aplicação de questionários, além de 5 entrevistas orais, com 5 professoras do AEE de 5 escolas sorteadas. A pesquisa explicitou que a maioria das professoras tem formação em Pedagogia, sendo que a maioria trabalha com contratos temporários. Além disso, para elas, a maioria das professoras não reconhece o papel do AEE como uma importante ferramenta no desenvolvimento dos alunos com deficiência, mesmo entendendo que no AEE se foca nas potencialidades e não na deficiência do aluno. Reclamam também da falta de apoio da equipe escolar e dos professores, da dificuldade dos outros docentes em receber ajuda da professora do AEE, além da alta carga de trabalho. Percebe-se nesse estudo que mesmo não tratando diretamente de condições de trabalho docente, os resultados são extremamente pertinentes no que diz respeito a uma análise comparativa.

A pesquisa de Rabock (2016) tem como objetivo investigar a concepção de professoras de AEE sobre infância, aprendizagem e desenvolvimento, e como essas concepções relacionam-se com o seu trabalho. Foram realizadas entrevistas semiestruturadas com 5 professoras de Educação Infantil da rede municipal de ensino de Joinville-SC. A pesquisa evidenciou que as professoras apresentam uma concepção de criança e infância desconectada de 
um caráter histórico e cultural e que elas acreditam que o trabalho do AEE na Educação Infantil é mais fácil, sob a justificativa de que nessa fase tudo está naturalmente pronto para possibilitar a aprendizagem das crianças. A autora expõe ainda que predomina uma imagem da criança com deficiência com um viés patológico, que precisa ser curada. Verificou-se ainda a necessidade de maior comunicação entre professores, famílias e profissionais de saúde no processo de desenvolvimento das crianças público-alvo da Educação Especial.

Sobre identidade docente temos 2 estudos (DORNELES, 2013; SANTOS, 2016).

O estudo de Dorneles (2013) discutiu como os discursos produzidos no dia a dia do AEE vêm criando maneiras de ser professor de Educação Especial na educação inclusiva e quais são as implicações desses discursos em suas práticas pedagógicas. Os sujeitos da pesquisa foram 6 professoras de Educação Especial que atuam no AEE e que se formaram no curso de Educação Especial da Universidade Federal de Santa Maria. Elas relataram suas experiências na prática educativa e como foi a sua constituição como docente. A autora notou que as professoras pesquisadas estão vivenciando situações conflitantes no que se refere ao trabalho na Sala de Recursos Multifuncionais e não se sentem seguras no que diz respeito ao seu papel na escola, pois ao mesmo tempo em que lhe são delegadas várias atribuições, são deixadas à margem das ações pedagógicas.

Santos (2016), em sua dissertação, procurou investigar como os professores que atuam na rede municipal de ensino de Joinville-SC se tornaram docentes no AEE. A metodologia teve como base a narrativa de história de vida. Foram entrevistadas 5 professoras que atuam no AEE desde o início de sua implementação no município. Os resultados revelaram que a escolha profissional pela docência foi caracterizada por tensões e o modo como as professoras aproximaram-se do AEE comprovou a existência de perfil de docente para atuar na Educação Especial que circunda as escolas e influencia no processo de constituição das identidades docentes.

Tendo como foco a avaliação, temos os estudos de Rios (2013), que teve por objetivo descobrir quais as implicações dos discursos acerca da avaliação feita pelos professores no atendimento do AEE no município de Florianópolis-SC. A análise da pesquisa foi dividida por dois grupos de materiais: os documentos referentes à legislação e 194 relatórios avaliativos produzidos pelos professores, referentes aos alunos atendidos no AEE. Os resultados apontaram que mesmo que a legislação expresse o entendimento de que a avaliação é uma possibilidade de identificação e categorização diagnóstica e um mecanismo de controle dos alunos, a procura pelo diagnóstico expõe a obrigação de normalização como tática para o controle e disciplina dos alunos considerados à margem do que é estabelecido como normal.

O estudo de Rosa (2015) teve como objetivo geral analisar os fatores do trabalho que contribuem para o bem-estar dos professores das salas de recursos multifuncionais para atendimento educacional especializado a alunos com surdez. Os sujeitos da pesquisa foram 5 professoras que atuam nas salas de recursos multifuncionais para atendimento educacional especializado a alunos com surdez, na rede de ensino do município de Campo Grande-MS. Como instrumentos de coleta de dados foram utilizados o questionário e as entrevistas semiestruturadas. Foi traçado o perfil sociodemográfico, o grau de satisfação dos docentes com as condições do trabalho, a satisfação/ insatisfação dos professores com as formações específicas que realizaram na área da educação especial. De acordo com os resultados, os professores analisados estão satisfeitos com os seus elementos do trabalho docente, destacando altos índices de satisfação, principalmente no que diz respeito ao uso da criatividade, à própria identificação com o trabalho realizado, ao reconhecimento do trabalho realizado e à satisfação na formação continuada efetiva. Todavia, apresentam como elementos negativos a falta de uma rede de discussão entre os profissionais da área para trocarem experiências e a insatisfação no que diz respeito às instalações e às condições gerais de infraestrutura física.

Sobre o foco na produção do conhecimento, temos o estudo de Borges (2014), que teve como objetivo compreender o que é conhecimento complementar no processo de escolarização de alunos com deficiência e transtornos globais do desenvolvimento no contexto da escola comum. A metodologia utilizada foi uma pesquisa-ação 
colaborativo-crítica em uma escola da rede municipal da cidade de Serra-ES. Como instrumentos de coleta de dados foram utilizados os grupos focais, a observação participante e as entrevistas semiestruturadas. As conclusões do autor convergem para a ênfase da contribuição do atendimento educacional especializado como local importante no auxílio à construção dos conhecimentos escolares, agindo em articulação com o saber produzido na sala de aula comum. Além disso, o autor enfatiza o conhecimento complementar, na medida em que é necessário evidenciar a sala de aula e avaliar o processo de aprendizagem dos alunos, de forma a subsidiar as ações do trabalho do professor do atendimento educacional especializado.

\section{Considerações finais}

Foi possível perceber que os estudos encontrados sobre Trabalho docente e AEE tiveram como foco os seguintes elementos: Políticas Públicas, Prática pedagógica, Formação de professores, Tecnologias Assistivas, Discurso dos professores, Identidade docente, Bem-estar docente, Avaliação e Produção do conhecimento.

Entre os instrumentos metodológicos encon- trados, ainda que variando em nomenclatura e abordagem, percebeu-se prioritariamente o uso da entrevista, presente em 30 estudos, seguido da análise documental em 13, da observação em 15, da análise documental em 13, do grupo focal em 9 , do diário de campo e da dinâmica conversacional em 1 cada.

Como já foi destacado antes, embora seja evidente o aumento de trabalhos acadêmicos, podemos perceber o reduzido número de pesquisas a respeito deste tema nas regiões Norte e Nordeste, em comparação com as outras regiões do país, em especial o Sul e o Sudeste do Brasil.

É notória a grande variedade de estudos e seus diferentes focos, demonstrando o grande potencial de pesquisas sobre o Atendimento Educacional Especializado, não apenas relacionado com o trabalho docente, mas sim com diversas outras possibilidades.

Urge, então, que mais estudos sejam realizados, tendo como universo as cidades do interior dessas regiões do País, onde supõe-se que tanto as condições de trabalho docente quanto o Atendimento Educacional Especializado sofrem de forma amplificada. Entretanto, somente com novos estudos é possível confirmar tal hipótese.

\section{REFERÊNCIAS}

ALBUQUERQUE, Ednea Rodrigues de. Prática pedagógica inclusiva: um estudo de caso em escola com atendimento educacional especializado (AEE) em Jaboatão dos Guararapes-PE. 2014. 340p. Tese (Doutorado em Educação) - Universidade Federal de Pernambuco, Recife, 2014.

ALMEIDA, Leiva Marcia Rodrigues de. Educação inclusiva: um olhar sobre a formação de professores para o uso das tecnologias nas salas de recursos multifuncionais de escolas públicas estaduais de Campos BelosGoiás. 2014. 118p. Dissertação (Mestrado em Educação) - Universidade de Brasília, Brasília, DF, 2014.

ALVES, Carla Barbosa. Atendimento educacional especializado na rede municipal de Uberlândia: implantação, organização e desenvolvimento. 2015. 173p. Dissertação (Mestrado em Educação) - Universidade Federal de Uberlândia, Uberlândia, MG, 2015.

ALVES, Ligia Maria Acacio. Formação e práticas em salas de recursos multifuncionais de escolas estaduais referências em educação inclusiva. 2013. 153p. Dissertação (Mestrado em Educação) - Universidade do Estado do Pará, Belém, 2013.

BARRETTA, Emanuele Moura. Políticas públicas de educação especial na perspectiva inclusiva: avanços e impasses na implementação em escolas públicas do Município de Frederico Westphalen-RS. 2013. 120p. Dissertação (Mestrado em Educação) - Universidade Regional Integrada do Alto Uruguai e das Missões, Frederico Westphalen, RS, 2013.

BATISTA, Geisa Cristina. Atendimento educacional especializado: trabalho e formação docente. 2013. 174p. Dissertação (Mestrado em Educação) - Universidade Federal de Rondônia, Porto Velho, 2013.

BERNARDES, Cleide Aparecida Hoffmann. $O$ trabalho docente no atendimento educacional especializado 
pelas vozes de professoras especializadas. 2014. 182p. Dissertação (Mestrado em Educação) - Universidade da Região de Joinville, Joinville, SC, 2014.

BERNARDES, Cleide Aparecida Hoffmann; CORDEIRO, Aliciene Fusca Machado. O atendimento educacional especializado pelas vozes das professoras. Revista Eletrônica de Educação, v. 10, n. 1, p. 88-99, 2016.

BORGES, Carline Santos. Atendimento educacional especializado e os processos de conhecimento na escola comum. 2014. 210f. Dissertação (Mestrado em Educação) - Universidade Federal do Espírito Santo, Vitória, 2014.

BUIATTI, Viviane Prado. Atendimento educacional especializado: dimensão política, formação docente e concepções dos profissionais. 2013. 324f. Tese (Doutorado em Educação) - Universidade Federal de Uberlândia, Uberlândia, MG, 2013.

CALDAS, Wagner Kirmse. Tecnologia assistiva e computacional: contribuições para o atendimento educacional especializado e desafios na formação de professores. 2015. 214f. Tese (Doutorado em Educação) - Universidade Federal do Espírito Santo, Vitória, 2015.

CÂNDIDO, Flávia Ramos. Tecnologias assistivas e inclusão escolar: o uso do software GRID2 no atendimento educacional especializado a estudante com autismo em escola pública do Distrito Federal. 2015. 238f. Dissertação (Mestrado em Educação) - Universidade de Brasília, Brasília, DF, 2015.

COSTA, Erika de Souza. A inclusão do alunado do atendimento educacional especializado no município do Rio de Janeiro. 2015. 94p. Dissertação (Mestrado em Educação) - Universidade Federal do Rio de Janeiro, Rio de Janeiro, 2015.

COTONHOTO, Larissy Alves. Currículo e atendimento educacional especializado na educação infantil: possibilidades e desafios à inclusão escolar. 2014. 275p. Tese (Doutorado em Educação) - Universidade Federal do Espírito Santo, Vitória, 2014.

DORNELES, Marciele Vieira. Em cena: a constituição do professor do atendimento educacional especializado. 2013. 103p. Dissertação (Mestrado em Educação) - Universidade Federal de Santa Maria, Santa Maria, RS, 2013.

FELLINI, Dineia Ghizzo Neto. A política de educação inclusiva e o atendimento educacional especializado na rede regular de ensino: um olhar sobre a região Nordeste. 2013. 173p. Dissertação (Mestrado em Educação) Universidade Estadual de Maringá, Maringá, PR, 2013.

FETTBACK, Carin Schultze. Uma contribuição ao estudo das relações entre família, escola e atendimento educacional (AEE) no contexto da educação especial na perspectiva da educação inclusiva. 2013. 204p. Dissertação (Mestrado em Educação) - Universidade da Região de Joinville, Joinville, SC, 2013.

FONSECA, Janini Galvão. O atendimento educacional especializado e o uso das tecnologias nas salas de recursos multifuncionais no ensino médio público do Distrito Federal. 2015. 126p. Dissertação (Mestrado em Educação) - Universidade de Brasília, Brasília, DF, 2015.

FUCK, Andreia Heiderscheidt. $\mathbf{O}$ atendimento educacional especializado nas salas de recursos multifuncionais na concepção dos professores da sala comum. 2014. 190p. Dissertação (Mestrado em Educação) - Universidade da Região de Joinville, Joinville, SC, 2014.

LUNA, Christiane Freitas. Sala de recursos multifuncionais (SRM): uma política pública em ação no Sudoeste baiano. 2015. 223p. Tese (Doutorado em Educação) - Universidade Federal da Bahia, Salvador, 2015.

LYRA, Juliana Chueire. Atendimento educacional especializado de alunos com altas habilidades/superdotação na cidade de Londrina, Paraná: um estudo de caso. 2013. 143p. Dissertação (Mestrado em Educação) - Universidade Estadual de Londrina, Londrina, PR, 2013.

NASCIMENTO, Alice Pilon do. Dialogando com as salas de aula comuns e o atendimento educacional especializado: possibilidades, movimentos e tensões. 2013. 227p. Dissertação (Mestrado em Educação) - Universidade Federal do Espírito Santo, Vitória, 2013.

PALMA, Debora Teresa. Escolas do campo e atendimento educacional especializado em sala de recursos multifuncional. 2016. 142p. Dissertação (Mestrado em Educação) - Universidade Estadual Paulista Júlio de Mesquita Filho, Araraquara, SP, 2016.

PORTO, Patrícia Padilha. Caracterização do atendimento educacional especializado em sala de recursos multifuncional: um estudo do contexto paranaense. 2014. 139p. Dissertação (Mestrado em Educação) - Universidade 
Estadual de Londrina, Londrina, PR, 2014.

RABOCK, Daiana. Concepções das professoras do atendimento educacional especializado com foco em crianças dos centros de educação infantil. 2016. 97p. Dissertação (Mestrado em Educação) - Universidade da Região de Joinville, Joinville, SC, 2016.

REIS, Claudinei Vieira dos. Tecnologia assistiva na perspectiva das professoras de atendimento educacional especializado no Sudeste goiano. 2014. 131p. Dissertação (Mestrado em Educação) - Universidade Federal de Goiás, Catalão, GO, 2014.

REVELANTE, Patricia. Políticas públicas inclusivas: implicações na formação de professores para o atendimento educacional especializado. 2013. 100p. Dissertação (Mestrado em Educação) - Universidade de Santa Cruz do Sul, Santa Cruz do Sul, RS, 2013.

RIBEIRO, Ruth Barbosa de Araújo. Conscientização e autonomia: desafios e possibilidades na formação continuada do professor de atendimento educacional especializado (AEE). 2015. 107p. Dissertação (Mestrado em Educação) - Universidade Federal da Paraíba, João Pessoa, 2015.

RIOS, Grasiela Maria Silva. Avaliação em educação especial: tecnologia de governamento no atendimento educacional especializado. 2013. 149p. Dissertação (Mestrado em Educação) - Universidade Federal de Santa Maria, Santa Maria, RS, 2013.

ROCHA. Roselene Nunes. Política de inclusão escolar na ótica de professores de sala de recursos multifuncionais da rede municipal de Florianópolis-SC. 2014. 114p. Dissertação (Mestrado em Educação) - Universidade do Vale do Itajaí, Itajaí, SC, 2014.

ROSA, Ana Paula Teixeira Minari da. $O$ bem-estar no trabalho dos professores das salas de recursos multifuncionais - surdez. 2015. 118f. Dissertação (Mestrado em Educação) - Universidade Católica Dom Bosco, Campo Grande, MS, 2015.

SALOMÃO, Bianca Regina de Lima. O atendimento educacional especializado em uma sala de recursos de Brasília: a sistematização do atendimento e o uso do computador como apoio pedagógico - um estudo de caso. 2013. 152p. Dissertação (Mestrado em Educação) - Universidade de Brasília, Brasília, DF, 2013.

SANTOS, Juliana Testoni dos. Professoras atuantes no atendimento educacional especializado e suas histórias de vida: um estudo sobre identidade docente. 2016. 114p. Dissertação (Mestrado em Educação) - Universidade da Região de Joinville, Joinville, SC, 2016.

SILVA, Cleudia Maria Ferreira da. A tecnologia assistiva nas salas de atendimento educacional especializado - AEE no município de Teresina-PI. 2014. 117p. Dissertação (Mestrado em Educação) - Universidade Federal do Piauí, Teresina, 2014.

SILVA, Marcia Rodrigues da. A formação dos professores de atendimento educacional especializado de Goiás. 2014. 208p. Dissertação (Mestrado em Educação) - Universidade Federal de Goiás, Catalão, GO, 2014.

SILVA, Mara Cristina Fortuna da. O atendimento educacional especializado e o processo de escolarização dos alunos com deficiência. 2015. 157p. Dissertação (Mestrado em Educação) - Universidade Federal da Fronteira Sul, Chapecó, SC, 2015.

SILVA, Suzana Sirlene da. Salas de recursos multifuncionais: contexto de inclusão escolar para os alunos público-alvo da Educação Especial? 2015. 177p. Dissertação (Mestrado em Educação) - Universidade Estadual Paulista Júlio de Mesquita Filho, Araraquara, SP, 2015.

SOUZA, Ivete Cristina de. Sala de recursos multifuncionais e sala comum: a deficiência intelectual em foco. 2013. 133p. Dissertação (Mestrado em Educação) - Universidade Federal de Uberlândia, Uberlândia, MG, 2013.

TIBOLA, Carina Luisa Kurek. Políticas de educação especial na perspectiva da educação inclusiva: dos aspectos legais à implementação do atendimento educacional especializado - AEE. 2014. 134f. Dissertação (Mestrado em Educação) - Universidade Regional Integrada do Alto Uruguai e das Missões, Frederico Westphalen, RS, 2014.

VAZ, Kamille. O professor de educação especial nas políticas de perspectiva inclusiva no Brasil: concepções em disputa. 2013. 237p. Dissertação (Mestrado em Educação) - Universidade Federal de Santa Catarina, Florianópolis, 2013.

VIEGAS, Luciane Torezan. Educação especial no Rio Grande do Sul: uma análise da oferta e das políticas 
educacionais no período de 1988 a 2002. 2005. 119p. Dissertação (Mestrado em Educação) - Universidade Federal do Rio Grande do Sul, Porto Alegre, 2005.

ZUQUI, Francielle Sesana. As salas de recursos multifuncionais/salas de recursos das escolas da rede municipal de educação do município de São Mateus: itinerários e diversos olhares. 2013. 231p. Dissertação (Mestrado em Educação) - Universidade Federal do Espírito Santo, Vitória, 2013.

Recebido: 19/06/2017

Aprovado: 18/11/2017 